\title{
Meta-Analysis the Effectiveness of McKenzie Exercise to Reduce Pain in Patients with Non-Specific Low Back Pain
}

\author{
Sima Asmara Dewa Marya Mahardika Putri'), Agus Kristiyanto²), \\ Hanung Prasetya ${ }^{3)}$ \\ 1) Masters Program in Public Health, Universitas Sebelas Maret \\ 2)Faculty of Sport Education,Universitas SebelasMaret \\ 3)Study Program of Acupuntur, Health Polytechnics, Ministry of Health Surakarta
}

\section{ABSTRACT}

Background: Low back pain (LBP) is defined as a symptom that cannot be specifically validated. LBP is one of the most common forms of musculoskeletal disorders. Anyone can experience lower back pain throughout his life, because LBP is back pain without any underlying abnormalities. There are many exercises that can be given to treat this LBP, one of which is the McKenzie Exercise. The principle of this exercise is to improve posture to reduce lumbar hyperlordosis. This study aims to analyze the effectiveness of the McKenzie Exercise for pain reduction in patients with non-specific LBP.

Subjects and Method: This was a systematic review and meta-analysis carried out with the PRISM flow diagram. Search for articles through journal databases includes: PubMed, Science Direct, Google Schoolar and PEDro by selecting articles published in 2010-2020. The keywords used were ("LBP" OR "Low Back Pain") AND ("McKenzie Exercise" OR "Therapy") AND "randomized controlled trial". The inclusion criteria were full paper articles with the Randomized Controlled Trial (RCT), the size of the relationship used with the Mean SD, the intervention given was McKenzie Exercise, the study subjects had an age range of 18-65 years, and experienced non-specific low back pain, without radicular pain. Eligible articles were analyzed using the Revman 5.3.

Results: A meta-analysis of 11 articles showed that the McKenzie Exercise was able to reduce pain in patients with non-specific low back pain by 0.44 times compared to other interventions or no intervention. (SMD -0.44; 95\% CI $=-1.06$ to $0.18 ; \mathrm{p}=0.16)$.

Conclusion: McKenzie Exercise has a weak effect to reduce pain in patients with nonspecific low back pain.

Keywords: McKenzie exercise, low back pain, pain, meta-analysis

\section{Correspondence:}

Sima Asmara Dewa Marya Mahardika Putri. Masters Program in Public Health, Universitas Sebelas Maret, Jl. Ir. Sutami 36A, Surakarta 57126, Central Java. Email: simaasmara@gmail.com. Mobile: 082140354882.

\section{Cite this as:}

Putri SADMM, Kristiyanto A, Prasetya H (2021). Meta-Analysis the Effectiveness of McKenzie Exerciseto Reduce Pain in Patients with Non-Specific Low Back Pain. J Epidemiol Public Health. 06(01): 33-41. https://doi.org/10.26911/jepublichealth.2021.06.01.04.

cC (i) (2) Journal of Epidemiology and Public Healthis licensed under a Creative Commons Journal of Epidemiology and Public Healthis licensed under a Creation
Attribution-NonCommercial-ShareAlike 4.0 International License.

\section{BACKGROUND}

Low Back Pain is defined as a symptom that cannot be specifically validated. Low back pain is a disorder with several possible etiologies occurring in many population groups. LBP is one of the most common forms of musculoskeletal disorders. Anyone can experience lower back pain throughout his life, because LBP is back pain without any underlying abnormalities. One of the problems that often occurs, where the pain is felt in the lumbosacral area to the thigh (Hartvigsen et al., 2018). Acute non-specific LBP has duration of less than 6 weeks, whereas chronic non-specific LBP occurs 
more than 12 weeks or for approximately 3 months (Kisner et al., 2018).

The prevalence for the incidence of low back pain varies widely each year, reaching 15-45\%. According to WHO (2019) low back pain is the leading cause of disability worldwide with a global prevalence of $7.2 \%$, affecting 4 out of 5 people in their lifetime. About $12.5 \%$ of people in the UK report experiencing low back pain. In America it reaches $8-56 \%$ of people experiencing back pain and within 3 months about $26 \%$ of people reported experiencing LBP every day (Wong et al., 2017). In Finland it is reported that $33 \%$ of women and $29 \%$ of men experience low back pain (Paatelma et al., 2008). The exact incidence rate of low back pain in Indonesia is estimated to vary between $7.6 \%$ to $37 \%$. The occupation of farmers, fishermen or laborers is the highest prevalence for musculoskeletal diagnosis with a rate of $31.2 \%$ (Andini, 2015).

Low back pain (LBP) can be caused by several things and wrong habits. LBP can arise due to errors that occur continuously and repeatedly, such as the habit of working in a bent position for too long. It is lifting weights in an ergonomic position, with spinal abnormalities, or due to degenerative diseases. The more often these recurring mistakes occur and as a person gets older, the risk of suffering from LBP will be bad. The peak occurrence of low back pain is between the ages of 30 and 55 years (Flavell et al., 2016). There are many exercises that can be given for handling this LBP, one of which is McKenzie. This exercise invented by Robin McKenzie is also known as diagnostic and mechanical therapy. This method is very commonly used by physiotherapists as an effective method for dealing with LBP (Alhakami et al., 2019).
McKenzie exercise is one of the repetitive exercise techniques with extension movements, which aims to strengthen and stretch the extensor and flexor muscles of the lumbo sacral joint which can reduce pain. The principle of this exercise is to improve posture to reduce lumbar hyperlordosis. McKenzie Exercise is an effective intervention for musculoskeletal problems. McKenzie exercise is given to mobilization, manipulation and strengthening exercises for the flexor muscles and extensor muscle stretches that can reduce pain (Petersen et al., 2015). Another way that can be done to reduce the pain scale, with acupuncture therapy. Acupuncture therapy is a therapeutic treatment by inserting needles into acupuncture points in the human body (Susilo et al., 2021).

Based on the high number of nonspecific low back pain sufferers and the need for proper treatment, the researchers are interested in examining the effectiveness of the McKenzie Exercise for pain reduction in non-specific low back pain sufferers. The data obtained will be analyzed using meta-analysis by synthesizing the results of studies conducted to reduce bias.

\section{SUBJECTS AND METHOD}

\section{StudyDesign}

The study design used in this study is a systematic review and meta-analysis, using the PRISMA flow diagram guidelines. The search for articles was carried out using a journal database which includes: PubMed, Science Direct, Google Schoolar and PEDro by selecting articles published in 20102020. The keywords used were ("LBP" OR "Low Back Pain") AND ("McKenzie Exercise" OR “Therapy") AND "randomized controlled trial".

\section{Inclusion Criteria}

In this study, the inclusion criteria were full 
Putri et al./ McKenzie Exercise to Reduce Pain in Patients with Non-Specific Low Back Pain

paper articles with the Randomized Controlled Trial (RCT) research method, the size of the relationship used was the Mean $\mathrm{SD}$, the intervention given was McKenzie Exercise. Study subjects ranged in age from 18 to 65 years and experienced non-specific low back pain without radicular pain.

\section{Exclusion Criteria}

The exclusion criteria in this study included articles published in addition to English and Indonesian, being pregnant, having had lower back surgery for less than 2 weeks, experiencing a Nucleus Pulposus Hernia (HNP), and pain lasting more than 3 months.

\section{Operational Definition of Variables}

In formulating research problems here using PICO. The population is people with Low Back Pain aged 18-65 years. Intervention is the McKenzie Exercise, with a comparison of no therapy McKenzie Exercise and the outcome is a decrease in the level of pain.

McKenzie Exercise is an exercise technique with extension movements, which aims to strengthen and stretch the extensor and flexor muscles of the lumbo sacral joint which can reduce pain. The principle of this exercise is to improve posture to reduce lumbar hyperlordosis.

Low Back Pain is a symptom that can be caused by several disorders or diseases with known or unknown causes.

Pain level is a measure of severe discomfort or discomfort sensation that can be conveyed by direct verbal communication or by description.

\section{Instruments}

Visual Analog Scale (VAS) and Numerical Rating Scale (NRS) are used as a pain measurement tool for Low Back Pain sufferers to test the McKenzie Exercise..

\section{Data Analysis}

Data analysis in this study was carried out using the Review Manager application (RevMan 5.3). Data were analyzed based on variations between studies by determining the use of the random effect analysis model. In this study using $\mathrm{I}^{2}$ to quantify the dispersion. The results of the data analysis are in the form of the effect size of the heterogeneity of the study, which later the results of the analyzed data will be interpreted in the form of a forest plot and funnel plot.

\section{RESULTS}

Research from the primary study regarding the effectiveness of McKenzie exercise for pain reduction in patients with low back pain included 11 articles with a total sample of 864 participants, 438 participants for the intervention and 426 participants for comparison. Articles were obtained from 5 continents, namely, 6 studies from the Asian continent, 2 from the European continent, 1 study on the African continent, 1 on the Australian continent, and 1 study on the South American continent. Each study had a sample of less than 100 participants. Outcomes for some of the articles called for a decrease in pain levels following the McKenzie Exercise intervention.

The search for articles was carried out using a database based on PRISMA. The flow diagram can be seen in Figure 1. Assessment of the quality of the study was carried out qualitatively and quantitatively. The quality assessment in this study uses a rigor score. Rigor in each primary study was assessed using an 8 item scale plus the item sample size ( $>100$ participants). Each assessment criterion is given a score of 1 (one) if 'yes' and o (zero) if 'no'. After assessing the quality of the study, 11 articles included in the quantitative meta-analysis synthesis process were analyzed using RevMan 5.3. 


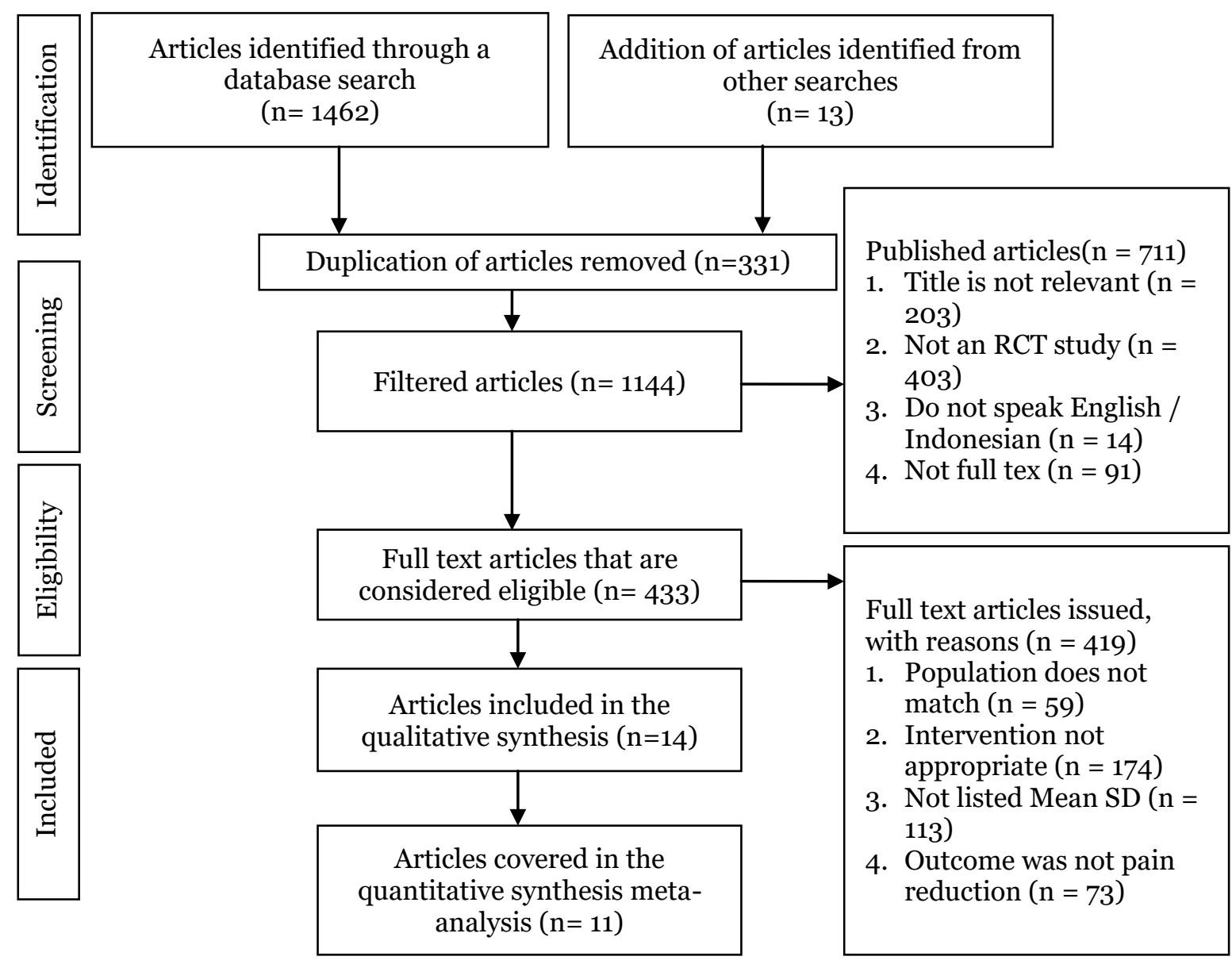

Figure 1. PRISMA flow diagram

\section{Forestplot}

Interpretation of the results from the metaanalysis process can be seen through a forest plot. Figure 2 shows as many as 11 articles reporting that the McKenzie Exercise can reduce pain in patients with non-specific low back pain compared to other interventions or not given intervention. Meanwhile, there was high heterogenity between experiments (I2 $=94 \%$; p $<0.001)$. Thus, the Random Effect Model is used in data analysis in the forest plot. The McKenzie Exercise was able to reduce pain in patients with non-specific low back pain by 0.44 times compared to other interventions or not given intervention, but it was not statistically significant $(\mathrm{SMD}=-0.44$; $95 \% \mathrm{CI}=-1.06$ to $0.18 ; \mathrm{p}=0.16$ )

\section{Funnel Plot}

A funnel plot is a plot that depicts the estimated effect size of each study on the estimate of its accuracy which is usually the standard error.

Figure 3 McKenzie Exercise funnel plot for pain reduction in patients with non-specific low back pain, showing that there is a publication bias characterized by asymmetry of right and left plots where there are 4 plots on the left and 7 plots on the right. The plot on the left of the graph has a standard error of 0.5 , while the plot on the right has a standard error of 0.4 . In addition, there are 2 plots on the right and left, each of which is away from the vertical center line. 
Putri et al./ McKenzie Exercise to Reduce Pain in Patients with Non-Specific Low Back Pain

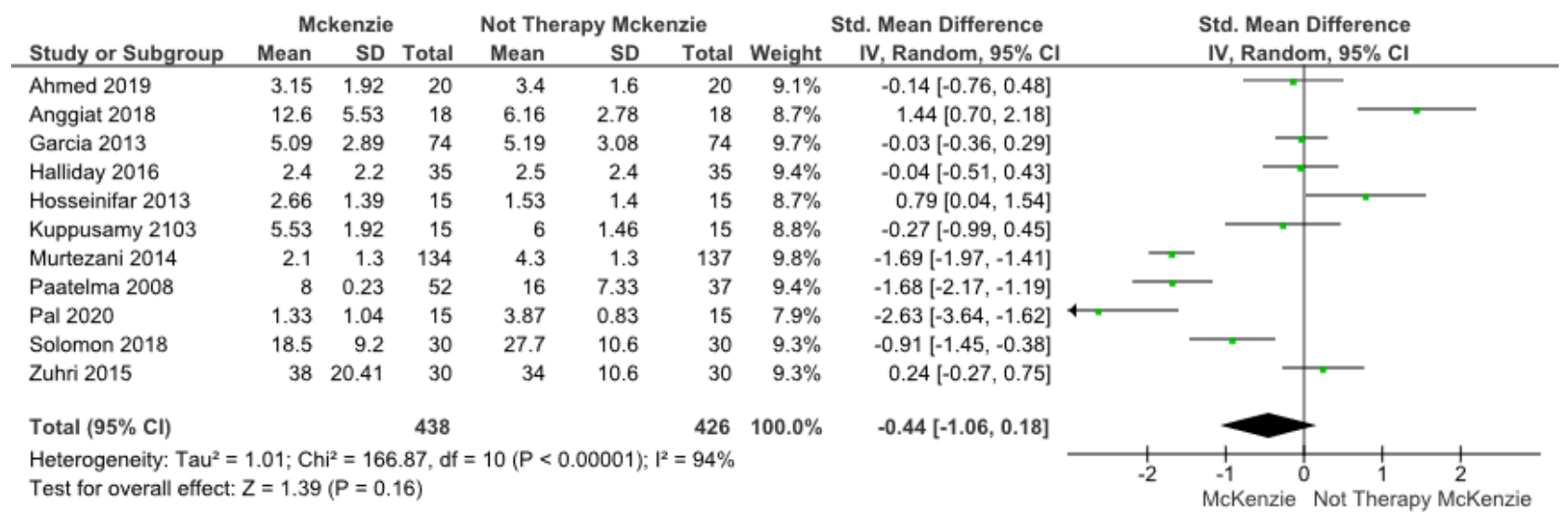

Figure 2. Forest plot of the McKenzie Exercise for pain reduction in patients with non-specific low back pain

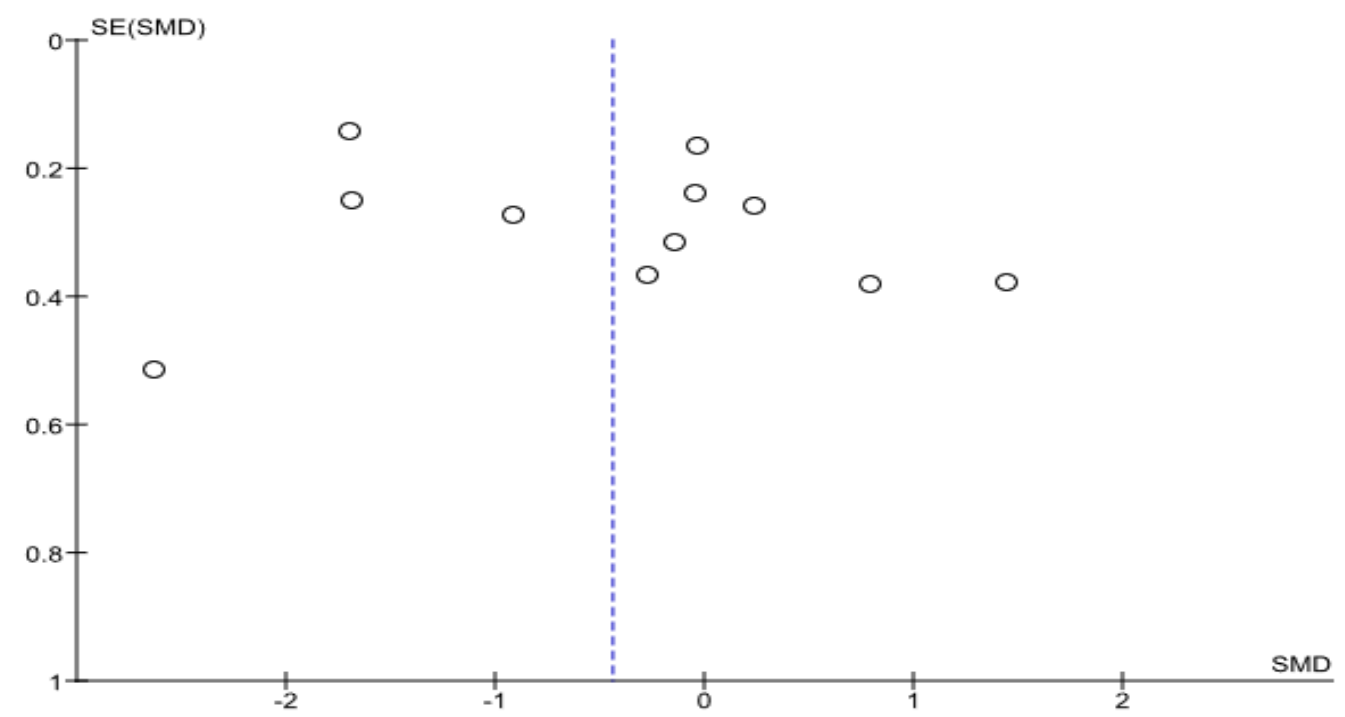

Figure 3. Forest plot of the McKenzie Exercise for pain reduction in patients with non-specific low back pain

\section{DISCUSSION}

Lower back pain is defined as pain, muscle tension or localized stiffness between the 12 ribs and above the inferior gluteal fold with or without leg pain. According to the World Health Organization, low back pain is the leading cause of disability (Pal and Sharda, 2020). Lower back pain occurs due to repeated and wrong habits. Acute nonspecific LBP has duration of less than 6 weeks, whereas chronic non-specific LBP occurs more than 12 weeks or for approximately 3 months (Kisner et al., 2018). McKenzie Exercise is an exercise technique with extension movements, which aim to strengthen and stretch the extensor and flexor muscles of the lumbo sacral joint which can reduce pain with muscle relaxation (Alhakami et al., 2019).

In this systematic review, 11 intervention study articles were identified worldwide from 2000 to 2020. This study analyzed from articles using the Mean SD measure. The results of the systematic review and meta-analysis are presented in the form of forest plots and funnel plots. 11 study articles designed with randomized controlled trials as a meta-analysis of the effectiveness of the McKenzie Exercise for 
pain reduction in patients with non-specific low back pain.

The results of the forest plot showed that McKenzie Exercise was able to reduce pain in patients with non-specific low back pain by 0.44 times compared to other interventions or not given intervention, but it was not statistically significant $(\mathrm{SMD}=$ $0.44 ; 95 \% \mathrm{CI}=-1.06$ to $0.18 ; \mathrm{p}=0.16$ ).

The results of this study are in line with Garcia et al. (2013) who stated that the McKenzie method is better than other interventions to reduce pain, such as the Williams method, because the McKenzie Exercise is an active exercise and is an effective intervention for musculoskeletal problems with evaluation. In line with this, Namnaqani et al. (2019) reported that the McKenzie method was effective in reducing pain in the short term than the Manual Therapy method. In addition, the Visual Analog Scale (VAS) measurement tool has been reviewed as a measuring tool that is quite valid in its use in trials.

Clare (2004) reported that the McKenzie Exercise therapy resulted in a reduction for low back pain patients than other standard therapies. This is because the reduction in pain is probably due to the training mechanism that uses the principle of vascular repair so that metabolite removal and algogenic pain occur. In addition, the McKenzie exercise will reduce pressure on the posterior annulus fibrosus through extension movements, so that pain is reduced.

The findings of this study are also in line with a study conducted by Pratama et al. (2020) which also proved that McKenzie exercise can reduce the level of pain in low back pain. The degree to which this pain scale decreases can be attributed to the back training movement which functions to dilate the blood vessels.
The smooth circulation of the blood can be followed by reduced muscle spasm, which relaxes the muscles and activates the release of the endorphin system in the blood which results in less pain. This is reinforced by Moldovan (2013), which states that McKenzie Exercise is more effective than Williams Flexion in reducing low back pain. This is because the principle of McKenzie's exercise is to improve posture to reduce lumbar hyperlordosis. While operationally the provision of exercises to strengthen the lower back muscles is aimed at relaxing the muscles, strengthening the lumbosacral muscles, especially the abdominal wall muscles and the gluteus muscles, stretching the shortened muscles, especially the extensor muscles of the lower back, hamstring and quadratus lumborum muscles posture correction. This is in accordance with the opinion of Kisner and Colby (2007), stretching or stretching contained in the McKenzie exercise can prevent tissue adhesions, maintain elasticcity and contractility of muscle tissue and prevent the formation of inflammation in the joint cavity so that the scope of joint motion can be repaired and maintained.

This study is not in line with several studies by Hosseinifar and Akbar (2013), Szulc et al., (2015), Kuppsamy et al., (2013), Zuhri and Rustanty (2015), reporting McKenzie's exercise intervention with a combination of other exercises or electrotherapy more effective in reducing pain. The primary study reported significantly the administration of other exercise interventions or electrotherapy in LBP sufferers.

According to Pal and Sharda (2020) in their study, adding a combination of McKenzie exercise with Short Wave Diathermy (SWD) and Transcutural Electrical Nerve Stimulation (TENS) is more effective in reducing pain in non-specific low back pain. This is due to the presence of short 
Putri et al./ McKenzie Exercise to Reduce Pain in Patients with Non-Specific Low Back Pain

wave diathermy which means a deep heating modality of physical therapy. It has a significant effect on pain relief and increased temperature in the tissues due to increased heat in the arterioles and capillary dilation followed by increased blood flow to the area. The increase in temperature alters the physical properties of fibrotic tissue such as those found in tendons, joint capsules, scars, and tissues making it easier to stretch when heated.

According to Khan et al. (2013) modality in heating is more effective than superficial heat in pain management in chronic low back pain patients. The application of TENS can also relieve pain in lower back pain, because the stimulation mechanism is a pain reliever based on the Gate of Control theory conceptualized by Melzack and Wall.

\section{AUTHORS CONTRIBUTION}

Sima Asmara Dewa Marya Mahardika Putri is the main researcher who selects topics, searches and collects research data. Agus Kristiyanto and Hanung Prasetya analyzed data and reviewed research documents.

\section{FUNDING AND SPONSORSHIP}

This study is self-funded.

\section{CONFLICT OF INTEREST}

There is no conflict of interest in this study.

\section{ACKNOWLEDGMENT}

Researchers would like to thank all those who helped compile this article and also thank the database providers PubMed, ScienceDirect, Google Scholardan PEDro.

\section{REFERENCES}

Alhakami AM, Davis S, Qasheesh M, Shaphe A, Chahal A (2019). Effects of McKenzie and stabilization exercises in reducing pain intensity and functional disability in individuals with nonspecific chronic low back pain: a systematic review.J Phys Ther Sci. 31(7): 590-597. DOI: 10.1589/jpts.31.590.

Andini F (2015). Risk factors of low back pain in workers. J Majority. 4:12. https://juke.kedokteran.unila.ac.id/index.php/majority/article/view/495.

Clare HA, Adams R, Maher CG (2004). A systematic review of efficacy of McKenzie therapy for spinal pain. Aust J of Phys. 5O(4): 209-216. DOI: 10.1016/Sooo4-9514(14)60110-0.

Flavell CA, Gordon S, Marshman L (2016). Classification characteristics of a chronic low back pain population using a combined McKenzie and patho-anatomical assessment.J Man Manip Ther. 26: 201-207. DOI: 10.1016/j.math.2016.10.002.

Garcia AN, Costa L da CM, da Silva TM, Gondo FLB, Cyrillo FN, Costa RA, Costa LOP (2013). Effectiveness of back school versus McKenzie exercises in patients with chronic nonspecific low back pain: A randomized controlled trial. Phys Ther J. 93(6): 729-747. DOI: 10.2522/ptj.20120414. Hartvigsen J, Hancock MJ, Kongsted A, Louw Q, Ferreira ML, Genevay S, Hoy $\mathrm{D}$, et al. (2018). What low back pain is and why we need to pay attention. Lancet. 391(10137): 2356-2367. DOI: 10.1016/So140-6736(18)30480-X.

Hosseinifar M, Akbari M, Behtash H, Amiri M, Sarrafzadeh J (2013). The effects of stabilization and McKenzie exercises on transverse abdominis and multifidus muscle thickness, pain, and disability: A randomized controlled trial in nonspecific chronic low back pain. J Phys Ther Sci. 25(12): 1541-1545. DOI: 10.1589/jpts.25.1541.

Khan S, Shamsi S, Samiha A (2013). Com- 
parative study of short wave diathermy and exercise together and exercise alone in the management of chronic back pain. Int J Health Sci Res 5(1): 156-164. https://www.ijhsr.org/IJHSR_Vol.3_Issue.9_Sep2013/2.pdf.

Kisner C, Colby LA (2007). Theraupeutic Exercise: Foundations and Techniques (Fifth Edit).Philadelphia. F.A. Davis Company.

Kisner C, Colby LA, Borstad J (2018). Therapeutic exercise: Foundations and techniques (Seven edit). Philadelphia. F.A. Davis Company.

Kuppusamy S, Narayanasamy R, Christopher J (2013). Effectiveness of McKenzie exercises and mat based pilates exercises in subjects with chronic non-specific low back pain: A comparative study. Int $\mathrm{J}$ Prev Treat. 2(4): 47-54. DOI: $10.5923 /$ j.ijpt.20130204.01.

McKenzie JE, Beller EM, Forbes AB. (2016). Introduction to systematic reviews and meta-analysis. In Respirology. 21(4): 626-637). DOI: 10.1111/resp.12783.

Moldovan M (2013). Therapeutic considerations and recovery in low back pain: Williams vs McKenzie. Phys Educ Sport J. 5(9). DOI: 10.2478/v10325012-0009-5.

Murti B (2018). Prinsip dan Metode Riset Epidemiologi (5tt ed). Program Studi Ilmu Kesehatan Masyarakat, Program Pasca Sarjana, Universitas Sebelas Maret.

Namnaqani FI, Mashabi AS, Yaseen KM, Alshehri MA (2019). The effectiveness of McKenzie method compared to manual therapy for treating chronic low back pain: A systematic review. J Musculoskelet Neuronal Interact. 19(4):492-499. https://pubmed.ncbi.nlm.nih.gov/31789300/.
Pal S, Sharda R (2020). Effectiveness of McKenzie exercises versus wii-fit yoga on pain and disability in patients with chronic non-specific low back variables independent variables. J Physiother Res. 4(1): 1-7. https://www.imedpub.com/articles/a-comparativestudy-to-see.

Petersen T, Christensen R, Juhl C (2015). Predicting a clinically important outcome in patients with low back pain following McKenzie therapy or spinal manipulation: A stratified analysis in a randomized controlled trial. BMC Musculoskelet Disord. 16(1): 1-7. DOI: 10.1186/s12891-015-0526-1.

Pratama W, Bustamam N, Zulfa F (2020). McKenzie exercise dan William'S flexion exercise efektif menurunkan intensitas low back pain. Jurnal Kesehatan Kusuma Husada. 42-52. DOI: 10.34035/jk.v12i1.547.

Susilo FE, Kristiyanto A, Prasetya H (2021). Meta analysis the effect of acupuncture therapy on pain reduction in osteoarthritis patients. Indones $\mathrm{J}$ Med. 06(1): 95-103. DOI: 10.26911/theijmed.2021.06.01.10.

Szulc P, Wendt M, Waszak M, Tomczak M, Cieślik K, Trzaska T. (2015). Impact of McKenzie method therapy enriched by muscular energy techniques on subjective and objective parameters related to spine function in patients with chronic low back pain.Med Sci Monit.21: 2918-2932. DOI: 10.12659/MSM.894261.

Wong AY, Karppinen J, Samartzis D (2017). Low back pain in older adults: risk factors, management options and future directions.Scoliosis Spinal Disord.12(1): 1-23. DOI: 10.1186/s13013017-0121-3.

Zuhri S, Rustanti M (2016). Efektivitas program back school dan teknik 
Putri et al./ McKenzie Exercise to Reduce Pain in Patients with Non-Specific Low Back Pain

mckenzie pada pasien nyeri punggung bawah (The effectiveness of back school programs and Mckenzie techniques in low back pain patients). Jurnal Keterapian Fisik, 1(1): 35-40. DOI: $10.37341 / \mathrm{jkf.v1i1.79.}$ 